Lo Bianco, Joseph (2004). Invented languages and new worlds. English Today 2, pp.8-18. DOI:

10.1017/S0266078404002032. http://journals.cambridge.org/abstract_S0266078404002032

Reprinted with permission.

\title{
Invented languages and new worlds
}

\section{Joseph Lo Bianco}

A discussion of the nature and significance of artificial languages

[A mildly adapted version of an article of the same name which first appeared in the journal Australian Language Matters, March 2002]

The life of a language involves relationships between linguistic elements and extra-linguistic contexts. The linguistic elements are varied and multiple, involving both written and spoken symbols and grammars, while the extra-linguistic contexts are the innumerable societies, cultures, and sub-cultures of humankind, including its worlds of reality, imagination, and ideology. This article discusses invented languages, partly in order to explore the motivations and schemes of their inventors and partly to compare languages created for international use (often called international auxiliary languages or IALs) with English, which itself functions as an IAL but is very much an uninvented language.

\section{Linguistic elements and extra-linguistic contexts}

Thousands of artificial languages have been created (cf. Baussani 1974, Large 1987, Schubert 1989) and the serious schemes that have produced more or less complete languages number many hundreds. There are three broad ways to classify invented, constructed or artificial languages: a priori languages; a posteriori languages and adapted or modified natural languages.

- A priori languages start from scratch with new symbols, signs or other elements devised to represent essential concepts. The new symbols and signs of the language, whether written or spoken, are then classified according to principles of some kind, usually a design logic the inventor considers critical to the communication problem he or she is trying to redress. Many of these schemes are sketchy and can't actually be called languages as such, often just remaining on the drawing board as language projects. However, a perhaps surprising number of a priori languages go beyond the private dreams of their often brilliant inventors and result in elaborate schemes combining thousands of elements of meaning into complex classification systems. Many are based on claims that the elements are universally understandable across human cultures, or that they are easily learned and globally valid. Typically a priori languages do not permit exceptions to their rules of use or grammar. Many a priori language projects pay little regard to the relevant extra-linguistic contexts and, inevitably (no matter how brilliantly conceived they are), they fail as IALs or in whatever other social, political or intellectual ambition inspired their original creation.

- A posteriori languages draw their building blocks from existing languages. Mostly these are natural languages but many a posteriori language projects use already existing but originally constructed languages as raw material for their linguistic elements. Several invented languages have been subjected to reform movements just like natural languages. The design principle behind a posteriori projects is a more pragmatic acceptance that a constructed language should not expect all present language users to abandon their existing speech or writing practices and adopt totally new ones in the pursuit of an ideal espoused by the language inventor. A posteriori projects therefore tend to take more seriously the extra-linguistic context but this does not necessarily guarantee success either. 
- Modifications and adaptations are often made to existing natural languages (whether tiny and endangered or large and dominant). These projects are even more pragmatic about extra-linguistic context, and usually aim to help an existing speech community adapt to altered and more challenging social environments. Partial modification includes efforts to revive dead or dying natural languages by devising new words, expressions, writing systems or other innovations so that they may take on new life in new domains, but even modifications to large and prominent international languages fit under this category, such as the various spelling reforms for English or specificpurpose codes such as Basic English and SeaSpeak. However, language reform movements of this kind are not much more successful than a priori and a posteriori invented languages.

\section{A priori invented languages}

One early effort at language construction was made in 1647 by Francis Lodwick in England. Calling his proposal A Common Writing, Lodwick imagined that by choosing 'radical' words and attaching what he considered commonly perceivable signs to such words, their meaning would become clear to readers who did not speak the original language of the word. Lodwick imagined that by adding such special signs to selected English words they would be rendered understandable to people who didn't speak any English, so that, say, non-English-speaking Russians or Greeks could somehow read English by virtue of an intuitive squiggle. Lodwick's scheme exemplifies an important aspect of many invented-language projects: the search for a system of universal signs that would mark ideas common to all people in all cultures.

This idealism pervades many invented-language projects, such as one in 1668 by another Englishman, Bishop John Wilkins, who thought that 40 basic categories encompass all human ideas and all existing entities. In both the spoken and written forms of Wilkins' scheme, each of the 40 core ideas was to be marked by a vowel, consonant or diacritic. People everywhere would do the same, and the collective effect (known as Real Character) would be a universal kind of writing. Through repetition and intuitive principles, we would learn the system, and on encountering a new language would instantly identify the core meanings through the standard markers. The central logic of the system would ensure that communication across language and cultural differences would be enhanced - even across languages that we do not speak.

Much more elaborately worked out is Ro, an extensive, logical and well-ordered language created in the United States by an Ohio Reverend, Edward Foster (1853-1937). Foster's life obsession produced a language in which, like Wilkins' approach, word categories are evident from letter selections, so that bofoc means red, bofod means orange and bofof means yellow. This sequence encapsulates Foster's desire to have written or printed words 'teach the learner' by having spelling hint at meanings.

Essentially Foster was seeking to devise alphabetic pictograms, a little like Chinese characters, with the letters of the Roman alphabet that English uses, so that a picture or image, or other semantic quality, was suggested in addition to the letter's existing correspondence with a sound. He described this process as 'self-interpreting'. Foster's main aim was not peace or universal communication, but to produce an inherently logical new language system; he was more focused on linguistic elements than extra-linguistic contexts. The increased logic in the language system would in turn enhance learning, improve acquisition, and stimulate better retention of ideas; but only indirectly would it also contribute to 'enlightenment and human progress'.

The first Ro publication emerged in 1906 and with energetic research and creativity 16,000 Ro/English words were devised. Devoting much of his life to the project, Foster added a veritable scaffold of consistency and logic to alphabetic writing by classifying every word he invented under 
letter categories according to rules that suggested that word's semantic properties. For example, words beginning with $B$ are for substances, initial $D$ words suggest place, $G$ suggests quality, and $J$ relationships. Vowel-initial words were for grammar, so that A words denote pronouns, E would denote verb inflections such as tense and mood, I and $O$ prepositions opposite to each other in meaning, while $U$ would be for conjunctions. The system is more complicated as it expands from two to three and multi-syllabic words. Two-part syllables connect a meaningful first consonant with significant vowels. By adding further semantically connected consonants, Ro produces three-part syllables and multiplies the logic by some order of magnitude.

Ro works its alphabetic wonders at the ends of words as well as their beginnings. Nouns, verbs, adjectives and adverbs are indicated by variations to final vowels of words. Via this rule, the last vowel $A$ indicates concrete nouns, $E$ indicates a verb, I an adverb, $O$ an adjective and $U$ an abstract noun. Foster suggested that Ro was as logical as a street map, though I guess he meant for those places where street names and house numbers follow a regular order and pattern, where nobody has knocked over the street sign, and an overgrown crab-apple doesn't hide the house number. These comments are not frivolous. In their seeming randomness and apparent disorder of variation, natural languages carry a great deal of cultural meaning for their users. Language variation is often for reasons that have little to do with the mere absence of systems of formal logic.

Although Foster was acknowledged in the US Congress, in libraries and among philanthropists, probably only a handful of people ever actually communicated in Ro (cf. Harrison, R., $<w w w$ langmaker.com/outpost/ro.htm>), whereas virtually everyone in the world uses illogical, random, incomplete and non-intuitive languages every day.

A more recent committee-created logic language that is also very impressive is Lojban ('logical language'). Lojban is intended to be spoken as well as written. Its express aims include removing 'a large portion of the ambiguity from human communication'. Work on Lojban has proceeded for some 50 years from its beginnings under Dr James Cooke Brown in 1955 (when it was known as Loglan) and has since involved hundreds of contributors. Lojban supporters call it unique in that it aims to be used among people and, eventually, between people and computers. In other respects it shares the aims of many invented-language projects that connect innovations in linguistic elements with extralinguistic social claims, as for example logic and rigor with cultural neutrality, phonetic spelling, and building millions of words from a fixed number of root words $(1,300)$, alongside claims to 'remove restrictions on creative and clear thought and communication'.

Since 1987, Lojban has been supported by the Logical Language Group, or la lojbangirz (pronounced 'lah-lozh-BAHN-geerz'), a not- for-profit company which maintains the official repository of its materials (cf. <http://www.lojban.org>). La lojbangirz has a journal, a newsletter and an annual LogFest to celebrate progress and developments. The Lojban project aims to work with Esperanto (see below) rather than against it, to advance the cause of international auxiliary languages. La lojbangirz also has purely scientific goals. It aims to teach Lojban, which it describes as 'cultureindependent', to groups of people so that scientific testing of the intellectual effects of language separated from cultural effects can proceed. In this way, influential theories in linguistics (such as the Sapir-Whorf hypothesis of linguistic relativity, the claim that different languages influence thought differently) can be empirically tested.

The projects of Lodwick and Wilkins, and of Ro, Lojban, and many other systems have sought perfection, either by constructing languages from scratch, or by modifying deficiencies in existing languages. As Eco (1997) has shown, there has been a 2,000-year search for various kinds of linguistic perfection. Some projects have aimed to overcome limits in expressive power and produce languages perfect for artistic imagination, others to produce languages without ambiguity (perfect for science and philosophy), others to produce languages neutral of ideology, interests, culture and 
nationality, and hence vehicles perfect for world citizenship, while some have aimed to produce languages so perfect that they overcome all limits of understanding and express transcendentalism, connection with God, communication with otherness, and spiritual perfection.

Such constructed languages are meant to be used by humans in giving life to new worlds of ideas, interests, art, politics and ideology, particular civilisations, gender, particular lifestyles, and the imagination. Some examples of new systems for ideal or imaginary worlds are described below.

\section{Láadan and Klingon}

Láadan attempts to reflect women's expressive uniqueness, finding this a deficiency in existing natural languages, and presumably in other invented languages. Created by Suzette Haden Elgin in the early 1980s in the United States, Láadan has a radical pronoun system and original ways of working such as morphemes based on speech acts and 'evidence acts'.

Unlike English, sentences in Láadan place the verb first, then the subject and object. A speech-act morpheme is placed at the beginning of sentences and an evidence-act morpheme at the end, the former indicating what kind of sentence follows (e.g., interrogative or imperative) while the latter shows whether the information in the sentence derives from personal experience, a trusted source, or a hypothetical source. These morphemes provide grammatical information that in English speech or writing we have to seek elsewhere. Although not obligatory for all sentences, evidence-act morphemes frame chunks of speech or writing and supply to participants in a conversation information about the authority basis of certain expressions. Other features are more conventionally feminist, as with gender in nouns. Gender is not normally marked but when it is marked the male category is specified by adding the suffix -id. For example, the word for parent is thul but with the addition of $-i d$ it becomes thulid ('male parent').

Like many contemporary invented-language projects, Láadan is premised on linguistic relativity, meaning that languages are not neutral vehicles for the transmission of 'out there' objective facts, but that subjectivity varies, not just across individuals, but predictably across groups, and that languages code, reflect, and are intimately bound up with this variation. Different perceptions of reality are coded and expressed in languages and in turn help construct interpretations of experience. In keeping with this ideology, Elgin's project speculates about what impact a language that expresses fundamentally different notions rooted in female experience and perception would have (or have had) on American culture. Unlike Lojban, which imagines it is possible to have language without culture or ideology, Láadan accepts that these go together and seeks to represent a neglected perspective. It exists in a literary space of its own, in the 1984 science fiction novel Native Tongue and its sequels, which have explored new worlds appropriate to a Láadaninfluenced reality. Because of Elgin's formal linguistic training, Láadan is also found in scholarly writing. See <http://www.inter-log.com/ kms/Laadan/learning.html>.

Many invented languages exist in imaginary space. Unlike those that attempt to impact on the hereand-now, a growing number of created languages exists for other-worldly reasons. Klingon makes big claims for itself, described on the Klingon Language Institute's website as the 'galaxy's fastest growing language'. Originating in the Star Trek TV series and movies (where other languages, such as Tamarian and Bajoran, are spoken), Klingon is perhaps the preferred language of space enthusiasts and those motivated towards alien communication. Like its better-known counterpart, the Académie française, the Klingon Language Institute (founded in 1992) tries to protect the purity of the language and develop its expressive range. The bumpy-headed aliens of Star Trek are not, in fact, the main users of Klingon but possibly thousands of otherwise normal earthlings who probably weren't interested in school French or Japanese but find Klingon the foreign language par excellence. With its own orthography (a script called plqaD) and a remarkable range of 
paraphernalia to support its development, Klingon provides an array of identity markers for users and learners. The 'Warrior's Tongue' is saturated with a distinctive culture, commercial merchandise, projects and activities, and supports scholarship through a journal $H o L Q e D$, as well as dictionaries and pocket guides, conversation books and audio cassettes. See <http://www.kli.org/>.

\section{Tolkien and Rowling}

Just as sci-fi imagination has its communication systems so too does the mythic past. The inhabitants of J. R. R. Tolkien's Middle Earth glory in a rich communicative repertoire. Tolkien was a professor of Anglo-Saxon, an accomplished student of Latin and Greek, and studied and spoke several other languages. In devising communication systems and histories for hobbits, orcs, elves and dwarves, he gave full rein to his many linguistic accomplishments, but reversed real-life experience in which language function usually precedes language form. Tolkien first created languages then invented worlds, discourses and roles so that his creations could run free. His work provides history, both fragmentary and complete, and a 'present' full of diverse names and naming practices. His language world is rich in diglossia, language ecology (shift, maintenance, and death), stable and ruptured bilingualism, culture and language connections and other features of linguistic variation and society/language correlations.

First the Elves divided into two main groups, the West Elves (the Eldar) and the East Elves. Among the Eldar, three tribes sailed from Beleriand to Valar and evolved a language called Quenya (also High Elven, High Elvish) which some commentators have called Elvish Latin. Quenya's distinctive writing system, Tengwar, has its own history of origination, modification and reform, each phase stimulated by the emergence of new communicative demands. A rival writing form, Certar, gives rise to digraphia in elvish writing. Certar (also called Cirth) is found mostly in the scratchings and inscriptions of Sindar Elves in Beleriand and is therefore archaic. Low Elven was called Sindarin or Gray-elven, and was originally the language of those who did not sail from Beleriand. Over time, Sindarin separated from Quenya, so that communication between West and East Elves became difficult. Some elves were expelled from their new lands and returned to Beleriand where they had to re-learn Sindarin, though they retained Quenya for ceremonial purposes and high occasions, reversing the High/Low split between the two languages.

As far as 'Men' were concerned Tolkien had another elaborate pattern. Most Men speak Westron. Some of the human tribes, whose ancestral language was Adunaic, had helped the Elves during the wars and turmoil in the times that precede the focus of most of Tolkien's books: times of legend, memory, and myth; tumultuous times when they fought The Dark Lord. They were rewarded with learning, long life and a new place to settle. In this new place, the human tribes learned Sindarin from the local Elves, though some spoke Quenya. As the humans mixed with other creatures so too did Adunaic mingle with other languages, eventually becoming the Common Speech, later called Westron, spoken in much of Middle Earth.

In the Lord of the Rings, language changes from archaic to more modern forms reflecting Tolkien's keen sense of the evolution of speech over time. The Hobbits did not have a distinctive language of their own, but used the language of Men. Hobbits underwent a major language shift, from Rohiric (which was used in their ancestral lands of Anduin and Mirkwood, from where they fled tumultuous events) to Westron, which they learned when they arrived in Eriador, their place of refuge.

There are other languages in the Lord of the Rings: the hard-to-learn language of the ancient treelike Ents, described as repetitive and poor sounding; the slow-changing language of the Dwarves, with its secret discourses and private speech; and the Black Speech of the Orcs, cobbled together from other languages as if to reflect their lack of virtue. In Tolkien's world, having an original speech and being separated from it suggests tragedy; while undergoing language shift implies pragmatism; 
having an original speech and retaining it connotes virtue, but 'cobbling together' suggests shiftiness. The Orcs pervert other tongues to their foul ends, with the detestable Sauron involved in inventing their language. Tolkien makes Orc-talk highly dialectal and primitive, precluding effective and elaborated communication, associating evil-doing with limited expressive range. Over time, however, the Orcs move to speaking a basic kind of Westron, and the evil Sauron's fall leads to the abandonment of Black Speech, but on his return it is revived as the language of his court, and is the language of the inscription on the Ring (cf. Noel 1980).

Far less elaborate than Tolkien's world of languages is J. K. Rowling's Hogwarts School, where Harry Potter and his friends learn wizardry, though here too there are critical social ideas implied in the uses of bilingualism and functional speech forms. For example, some Hogwarts students are parselmouths (speakers of parseltongue) and can communicate with snakes, which is essential for entering the Chamber of Secrets, guarded as it is by serpents. Rowling's deployment of language as an access code expresses the intercultural claims for languages common in books of the imagination, where closed-off spaces and places are revealed only to the communicatively initiated.

\section{Modifications to natural languages}

There are literally thousands of well-developed schemes to modify natural languages, and perhaps the greatest number are for modifying and reintroducing Latin. Some aim to undo the historical shifts from Latin to vernacular, others aim to send Latin back to the monastic scriptoria, while still others aim to make the most of the internationalisation of Latin words in many languages worldwide and in this way enhance international comprehension. Indeed, some seek no less than the restoration of Latin, and run radio and television programs with strong followings.

Perhaps the most famous of the Latin revivalists is Interlingua, invented in the early part of the 20th century by the Italian mathematician Giuseppe Peano, and also known as Latino sine Flexione (LsF) and Europeano. LsF is a successful invented language, partly because it is not completely an invention, and partly because it has stimulated dozens of schemes to simplify Latin. In effect, these schemes are modifications to a natural language, even though the natural language concerned is pretty dead. LsF is in effect Latin stripped of its case and verb inflections.

There is a modest and a more ambitious version of LsF. The modest version is Interlingua/Latino sine Flexione, which was not so much a revival of spoken Latin as a proposed written lingua franca for international scientific communication, in which Latin, shorn of its complex declensions and conjugations, was to be used for the preparation of technical papers in fields with extensive Latinderived terminology. Several ambitious versions of LsF are based on the claim that, since educated people across the world already share a large stock of vocabulary items (at least in basal form) from Latin and Greek, they can be expected to make educated guesses about the meanings of other Latinand Greek-derived words. By removing its complex inflections and changing its syntactic rules, Latin could be made more like such an 'analytic' language as English (that is, a language that does not heavily inflect its verbs and nouns), and could therefore unite people across the globe who cannot easily communicate at present.

Romanova is another interesting instance of Latin revivalism that reflects part of Peano's modest idea. It is a neo-Latin system aimed only at speakers of the main Romance languages (Spanish, French, Italian and Portuguese) and at achieving what its activists say is the realistic goal of enhancing the mutual intelligibility of these languages by stressing their common Latin connections. Similarly, supporters of Paris-based VoxLatina stress the active promotion of the Romance languages, and especially French, in a Europe that, they argue, is more wedded to English every year. 
Many IAL schemes stress non-European languages and small-against-large languages, examples of which are Tokana and Unish. Tokana takes its lexical and grammatical influences mainly from numerically small languages (such as Basque, Choctaw, Cree, Finnish, Greek, Hebrew, Hungarian, Irish, Kwakiutl, Lakota, Lamagasy, Quechua, Tagalog, and Warlpiri) and Welsh, though it borrows from large ones as well (French, German, Hindi and Spanish). Tokana is intended for the 'amusement and edification' of its inventor, who in this way explores his 'aesthetic impulses and theoretical ideas' <http://mpearson.narod.ru/tok.1.html>. It is a classic a posteriori language in that it tries to look and feel like a natural language by being based on natural languages. Since natural languages are always borrowing from and lending to each other, Tokana's borrowing and lending of words is like inventing natural processes. Its grammar is however constructed 'from the ground up' and is a good example of a fully hybrid project.

Also not dominated by European languages is Unish, the outcome of a major university effort. It has extensive Chinese, Japanese and Korean input but draws on a total of 16 languages: Arabic, Chinese, English, Esperanto, French, German, Greek, Hindi, Italian, Japanese, Korean, Latin, Malay, Portuguese, Russian and Spanish. Unish is a serious exercise in linguistic engineering complemented by a rich array of scholarly papers. Its rationale is a classic of the genre: 'As globalization continues apace, the demand for an international medium of communication has today become even more crucial.' As noted below, a productive time for invented languages was the dawn of the 20th century, when a global world was starting to seem possible. Today, however, we don't just imagine globalisation but live with it, and in the present-day reality of globalisation English has come to assume many of the functions of an IAL.

The devisers of Unish observe: 'Not a few problems arise when one particular language like English is adopted as a universal language since the people in English-speaking countries would be automatically vaulted into a privileged position. Additionally, English is difficult to learn due to its irregularity of grammar and pronunciation'

<http://www.unish.org>. This is the classic discourse of the IAL movement, that: speakers of any one natural language gain unfair advantage if that language is used for international communication; natural languages are in any case difficult to learn for speakers of languages from different language families; natural languages are full of irregularities and inconsistencies; and they are not neutral.

\section{Esperanto as the classic IAL}

The decades before and immediately after the end of the 19th century were a productive time for IALs. The imperial powers of Europe controlled much of the globe, maps were increasingly accurate and technological advances rapid. Travel and travel writing were producing a 'planetary consciousness' among Europeans (Pratt 1992) and it was becoming feasible that some kind of interconnected world system would emerge. Those who saw a global age coming tried to prepare for it in various ways, though for the most part they made only modest personal arrangements. Some, however, devised remarkable and ambitious schemes for all of humanity, working to establish world government, based on universal principles such as cultural equality, national sovereignty, personal emancipation and religious freedom. Others thought that technology would decide the world role of nations and tried to help their country's chances by inventing. Some invented languages.

Most famous among these inventors was a Polish oculist, Ludwig Zamenhof, who turned the focus of his daily attention from individual eyesight to social vision. In 1879, a German priest, Johan Martin Schleyer, had made public his world language project Volapük (a name meaning 'world language' in Volapük). Based largely on German and English, Volapük had an impact on other language projects of the time and especially on the most successful and best known of all, Zamenhof's, whose work on 
Esperanto started, it seems, when he was 15, growing up in multilingual but bitterly divided Bialystock. In later life he even devised a 'neutral' religion for the world, Homaranismo (Esperanto for 'member of the human race').

In 1887, his Universal Auxiliary Language for the global age was released. Zamenhof released it under the name 'Dr Esperanto', and perhaps because it did represent a kind of hope the name stuck. Unlike the names of most natural languages (that call to mind a nation, a people, or a territory), Esperanto names the dream of a world united by politically neutral speech, a communication system that would not favour any nation, people or ideology.

The century into which these ideals were launched however was not a period receptive to politically neutral and socially inclusive ideals, but a time of extreme and exclusive ideologies. Both Nazis and Soviets, suspicious of the congresses held to promulgate Zamenhof's dream, suppressed Esperanto (and Homaranismo) and persecuted its speakers. Many Esperantists were opposed to Homaranismo, pragmatically sensing that this made them look like a cult, an impression which placed further obstacles in the way of the language being accepted.

People often say that Esperanto has failed, and that its failure shows that artificial languages lack such cultural features as history, values, and literature, all of which are needed for the survival and prospering of a language. However, the report card some 115 years after its release is not so negative. Today perhaps several million people speak and study Esperanto, and from its home in Rotterdam the World Union of Esperantists maintains a network of more than 2,000 representatives in over 90 countries, publishes a lively literature, runs regular conferences and workshops, and encourages world organisations such as the UN and the EU to recognise it as the International Auxiliary Language. Esperanto motivates a lively discourse community in all parts of the world, is older than many languages that we happily describe as 'natural' today, even though they were the result of deliberate language planning in the post-colonial period of the 1950s and 1960s. It has also grown naturally so as to display all the qualities of a natural language, including its own kinds of accent and dialectal variation.

In October 1966, the Union of Esperanto Associations handed the Secretary General of the United Nations a proposal signed by more than a million people, and 3,843 organisations, claiming to represent 71 million people from all parts of the world, calling on the UN to 'solve the world language problem' by supporting the International Language. Thirty years later, in 1996, it issued the Prague Manifesto, in which the claims, ideas and thinking of what is now called the Movement for the International Language Esperanto shows that it has lost little of its fervour and idealism about the potential contribution of the language to the world, but now uses a vocabulary perfectly in tune with contemporary language-rights movements that seek to defend small and threatened languages. The Prague Manifesto bases its advocacy for the wider use of Esperanto on the following claims:

\section{Democracy}

Using existing languages of power is 'fundamentally antidemocratic'

\section{Global education}

Unlike 'ethnic' languages (such as English), Esperanto is not 'bound' to certain cultures and nations, being a 'language without borders'

\section{Effective education}

Many more learners can reach fluency in Esperanto than in traditional foreign languages Multilingualism

Esperanto is additional to existing languages, rather than replacing existing languages 
Language rights

Esperanto does not exacerbate the 'unequal distribution of power' between languages, but supports equal language rights

Language diversity

Esperanto sustains world language ecology rather than the present rapid extinction of languages

\section{Human emancipation}

Esperanto is described as 'one of the great functional projects for the emancipation of humankind' by allowing universal participation 'in the human community', so that while people remain 'securely rooted' in their local cultural and language identity they are not limited to it

\section{Esperanto's accompaniments, rivals and counterparts}

Apart from the persecution of the movement, Esperanto was also faced with language challenges when it became the object of active and controversial reform efforts. Some reformers sought to bring about minor simplifications (believing it to be obscure and clumsy in parts), while others wanted more radical change.

The greatest impact came from Ido. In its early congresses, Esperantists rejected suggested improvements to the language made by a group of people who came to be called the Idists. A full breakaway movement resulted, in which the Danish linguist Otto Jespersen and the French mathematician and philosopher Louis Couturat were prominent. The Jespersen and Couturat reform proposals drew on another contemporary invented language, Idiom Neutral, or Ido, along with their own suggestions for change. Ido enthusiasts claim that Zamenhof himself had actually proposed or supported some of the changes being put forward. The failure of these proposals led to the development of Ido as a proposed IAL, which shares many features with Esperanto, but has adopted a gender-neutral personal pronoun and discards the Esperanto requirement that adjectives agree in number and case with nouns they qualify. In addition, Ido has unvarying adjectives.

Idists, although today they are few, saw themselves carrying on from where Zamenhof had left off, though, like Esperanto itself, this is only true at the formal level of language design, since in terms of common usage fewer people have heard of Ido than of Esperanto. Nevertheless Idists have an international organisation, issue publications, and convene gatherings of different kinds, and continue to press their language. According to their website, Idists remain supportive of IALs in general and of Esperanto, but advance the particular cause of Ido.

In the early days of inventing IALs, a technical association was created at a global level to adjudicate the claims of various candidates for world language. Novial, which was also created by Otto Jespersen, was offered as a candidate for International Auxiliary Language in 1928, attracting considerable interest. Jespersen's long involvement in the International Auxiliary Languages movement, his active role in advocating Esperanto reform through Ido, his invention of Novial, and his formal linguistics training make him one of the major figures in the history of artificial languages (as well a major grammatical commentator on English). Novial (meaning new IAL: cf. Latin novus 'new') draws its vocabulary largely from the Romance and Germanic languages and much of its grammar from English. After Jespersen's death in 1943 little organisational structure remained, as a result of which Novial has largely disappeared. However, a small Internet-facilitated group of enthusiasts keeps working on, and with, Jespersen's special creation.

\section{Nations, languages, and ideals}

Volapük, Novial, Esperanto, Ido, Interlingua, Lojban, Unish, Idiom Neutral.... When we see these 
languages listed it brings home a point we are otherwise not used to noticing. Most languages carry the name of a nation, while artificial languages mostly carry the name of an ideal. The nation-naming of languages has its own complex history. Irish language activists call the language whose fortunes they advance Irish, those who oppose them or are not attuned to the debate, call it Gaelic. In Australia some call English, Australian English. I have heard people say that migrants should speak Australian, and, despite their usually venomous intention, from one kind of sociolinguistics, and from the theorisation of linguistics put forward by LePage and Tabouret-Keller (1985), who see language as 'acts of identity', there certainly is Australian, or are many Australians, spoken among Australians.

Scots, not Scottish English, is an independent language of Britain, largely without the huge French and Latin influence of the Norman conquest that changed English in England from 1066 onward. A constant struggle for Scots-language advocates is for Scots to be recognised as a language. Yet, in fact, Scots has many forms, just as there are several kinds of Scottish English with which it merges, but Scots is nonetheless a language of both antiquity and elaboration, in literature and in speech.

The very names of many languages are also claims - about peoplehood and about distinctiveness. The political history of language naming has a strong connection with the politics of state-making. What linguists might technically define as a 'dialect continuum', such as Hindi-Urdu, are in extralinguistic terms entities with dramatically important social, political, historical and religious reasons for being distinct languages. Like all languages, Hindi and Urdu are often continuous - and very large 'acts of identity'. Despite being very similar to Hindi, Urdu is written in the Perso-Arabic script, while Hindi is written in Devanagari (Sanskrit characters). Urdu borrows from Arabic and Persian, while Hindi makes an effort to preserve words of older Indian origin. Urdu is Pakistan's co-official language, Hindi is India's. Then add Panjabi, whose scripts and vocabulary are differentiated by religion, so that Hindus and Sikhs write Panjabi using Gurmukhi, while some Hindus write it in Devanagari. Muslims on the other hand write Panjabi using Perso-Arabic script.

It is evident from this brief description of a complex reality that linguistic elements take on differentiated meanings in extra-linguistic contexts. Script alone in this case invokes national allegiances, religious affiliations and different histories. Such extra-linguistic contexts powerfully differentiate the combinations of linguistic elements used, even in what linguists might describe as similar or identical languages. Comparably, in the former Yugoslavia, rival language-planning projects are making Bosnian, Croatian and Serbian diverge further from one another, invoking such matters as nation, creed, territory and contested history.

Times of major political change usually bring forth language-reform movements, and so the war of independence in America was a time rich with new language schemes. Immediately after independence in 1776, many tried to mark the United States as different from monarchical Britain, some calling for a uniquely American language that would make use of the large German and Dutch presence. Modifying existing natural languages to produce a 'politically correct' Germanic English, an espoused national hybrid, inventors set to work writing grammars, readers and vocabulary lists that biased English towards its German origins. Although they failed, in the twentieth century, specifically in 1923 and 1968, in both Congress and the Illinois State House attempts were made to declare 'American' (not 'English') the official language - in the latter case successfully.

\section{Value-free values}

Two main criteria, technical and normative, motivate IAL projects. The technical criteria involve manipulating linguistic elements to produce regular and logical patterns, in which meanings are more or less 'self-evident', resulting in languages that are 'easy to learn'. 
The normative criteria refer mainly to 'neutrality'. Neutrality is usually of two kinds: political neutrality (understood as not favouring the interests of particular countries) and kinds of ideological neutrality (concerning issues such as gender-framed worldviews, religious orientations, and comparable values and perspectives). The technical criteria have proved more or less achievable. A large number of logical, patterned, regular and intuitive languages have been invented - and more will be. The fact that there have been many solutions to the technical challenge, and that many of these are both elegant and efficient, suggests that even technical criteria are based on values and that these values are multiple and varied. It seems that multiple, legitimate and stable differences of perspective exist, even about matters of technique.

However, the normative criteria have proved far more problematic. During the heyday of the IALs (the end of the 19th and early 20th centuries in Europe), an Association of Scientific Academies was founded to adjudicate on competing claims for an IAL, and to determine, scientifically, 'the best one'. This modernist cultural confidence in techniques to solve substantive problems among competing interests, much criticised by post-modern scepticism, imagines that it is linguistic and not extralinguistic factors that determine the fortunes of an invented language being accepted and used as an auxiliary language.

But the international domination of English cannot be explained by any recourse to technical linguistic criteria. It is extra-linguistic contexts, and not any ease of learning or inherent rationality, that explains why it is instrumentally useful to know English in Tashkent, Oslo, Nairobi or Nagoya. English predominates because of a 'historical contingency arising from the mercantile and colonial expansion of the British Empire which was followed by American economic and technological hegemony' (Eco 1997:331). Never before has political globalisation been followed by economic globalisation in which the dominant force of both, though in each case a different polity, spoke the same language.

\section{English, values and a globalising world}

Despite both the predictions and hopes of language inventors, the language that today most resembles an IAL is not an artificial language, but a natural one, and not a language neutral of culture, ethnicity, nationalism and world- view, but one that is saturated with all of these. The actual IAL is not at all a simple, rational, regular, easy-to-learn, phonetic language whose verbs and nouns follow unvarying rules. Perhaps there is a fundamental problem with the notion of neutrality. Perhaps even languages like Lojban, despite impressive efforts to be 'culturally neutral', can only minimise some kinds of cultural patterning. Perhaps neutrality itself is a value. Perhaps formal order, unvarying regularity, intuitive character, and many of the other ideals that language inventors have espoused are also values and sustain their own ideology - that of rationality, formal order, simplicity, regularity and intuitive character.

English is almost none of the things the idealists imagined a world language would have to be, and a global world is very few of the things that they thought were inevitable. The global age isn't a world of nations alone, but a world of multiculturalism, economic globalisation and declining sovereignty in which many contradictory patterns co-occur (Giddens 1999) and in which new kinds of cultural identity emerge and disappear regularly. Even our views of culture have been radically challenged by the experience of post-modernity so that we cannot seriously defend notions of culture as fixed, unvarying, permanent and essential to identity, but we must concede that culture is an ensemble of practices that are variable and multiple.

Perhaps all languages, artificial and natural alike, are cultural once they come to be used by humans. Rather than aspire to rationality in languages perhaps it makes more sense to aim for multiplicity of perspectives. No language, not English nor Esperanto, in and of itself, certainly not structurally and probably in no other way, precludes its deployment for purposes different from any 
biases it may have organically located within its structure. This understanding does not mean that languages are not biased, or rather, that they are not culturally grounded, reflecting particular histories. Nor does this deny that languages can constrain and channel thought by pre-disposing speakers to some, and not other, meanings and interpretations. Rather it accepts that the users of a language are not necessarily consumed or exhausted by, or limited to, its biases and patterns.

This in turn does not mean that we should not be alert to the biases, the cultural predispositions and patterns that languages have and that they make available to their users. But languages are neither prison houses of the mind, nor are they transparent tools without interests, histories and tendencies. After all, the critical feature of language is not ultimately its structure but its use, that is, the practices that societies make available for language such as conversation, argument, debate, and discussion, tirades, ranting, lecturing, hectoring, persuasion and so on. These practices are often dialogical and iterative and make available possibilities and meanings well beyond any structural merits, or limits, in a language.

A large number of artificial language projects espouse ideological neutrality so as not to favour the interests, meanings, worldview, or experiences of dominant groups. However, what the language inventors produced were not languages lacking ideology, but languages saturated with contesting ideologies. The artificial-languages movement is testament to the power of idealism combined with a pragmatic, even fanatical, interest in grammar and lexicon. It has produced an immense gain in consciousness about language and thought, and reminds us that some groups benefit when their language is favoured. There is no end of concrete evidence of this. Some of the invented languages have become natural languages, part of the human linguistic repertoire, from which we can learn many lessons. One of these, as the on-going debates about the politics of English in the world remind us, is that there are both inequality and advantage in the world's present language arrangements.

\section{References}

Bausani, A. 1974. Le lingue inventate, Linguaggi artificiali, linguaggi segreti, linguaggi universali. Rome: Ubaldini.

Eco, U. 1997. The search for the perfect language. London: Fontana.

Giddens, A. 1999. Runaway world. London: Profile.

Large, A. 1987. The artificial language movement. Oxford \& New York: Blackwell.

LePage, R.B., \& A. Tabouret-Keller. 1985. Acts of Identity: Creole-based Approaches to Language and Ethnicity. Cambridge: University Press.

Noel, R. 1980. The Languages of Middle Earth. Boston: Houghton.

Pratt, M.L. 1992. Imperial Eyes: Travel Writing and Transculturation. London and New York: Routledge.

Schubert, K., ed. 1989. Interlinguistics: Aspects of the science of planned languages. New York and Berlin: Mouton. 



\section{University Library}

\section{- M M I E E R VA A gateway to Melbourne's research publications}

Minerva Access is the Institutional Repository of The University of Melbourne

Author/s:

LO BIANCO, J

Title:

Invented languages and new worlds

Date:

2004-04

Citation:

LO BIANCO, J. (2004). Invented languages and new worlds. English Today, 20 (2), pp.8-18. https://doi.org/10.1017/s0266078404002032.

Persistent Link:

http://hdl.handle.net/11343/112306 